\title{
Executivos e gerentes de empresas estatais às vésperas da privatização
}

\author{
Antonio José Pedroso Neto*
}

\section{Introdução}

Desde o início dos anos 1990, as empresas estatais brasileiras passaram por um amplo processo de privatização e de reestruturação societária, patrimonial e organizacional. Na segunda metade da década, o processo estendeuse às empresas do setor elétrico (Bndes, 2002, p. 41). No Estado de São Paulo, os dirigentes e demais funcionários das estatais paulistas do setor se depararam com a decisão firme do governador recém-eleito de prepará-las para uma possível privatização. Todos esses funcionários conheceram, já no início do novo governo, as iniciativas da Secretaria de Energia do Estado de São Paulo (Seesp) para dar início, andamento e cabo ao processo.

Antes, durante e após a privatização, as empresas passaram por um contexto marcado por diversas ações de mudanças organizacionais. Essas ações, no âmbito deste artigo, significam que as empresas realizaram, desde a des-

* Doutor em Ciências Sociais pela UFSCar; Membro do Núcleo de Estudos de Sociologia Econômica e das Finanças. Professor do Instituto Matonense Municipal de Ensino Superior —Immes. E-mail: ajpedrosoneto@uol.com.br

\begin{tabular}{|l|l|l|l|l|l|}
\hline Civitas & Porto Alegre & v. 7 & n. 1 & jan.-jun. 2007 & p. 86-108 \\
\hline
\end{tabular}


verticalização e a cisão de suas atividades por área (geração, transmissão e distribuição), até a subdivisão dessas áreas em unidades de negócios, passando pela introdução de tecnologias (administrativas, informacionais, de telecomunicação, de equipamentos), pela redistribuição do pessoal pelas novas subsidiárias criadas, pelo desligamento de pessoal via programas de incentivo, pela terceirização de atividades, por mudanças no sistema de suplementação de aposentadorias, pela promoção de treinamento de pessoal, de renegociação de contratos, de corte de gastos através de programas de austeridade financeira, etc. De modo geral, após a privatização, essas ações continuaram. Algumas ganharam relevância e foram mais impactantes, como aconteceu com o enxugamento do quadro de funcionários e com a implementação de tecnologias que substituem ou aumentam a produtividade da mão-de-obra de modo geral.

Tanto a privatização como as mudanças organizacionais foram realizadas sob incentivos e constrangimentos institucionais, políticos e econômicos. Entretanto, elas foram realizadas pelos próprios funcionários das empresas. Foram esses agentes, com longa história nas empresas e imersos em relações sociais locais, que mediaram os incentivos e os constrangimentos aludidos, e também contribuíram para criá-los.

$\mathrm{Na}$ bibliografia nacional mais especifica sobre as privatizações no setor elétrico, não há um estudo concreto e delimitado que tenha se empenhado em compreender como se deu a dinâmica do pessoal das empresas que levou a cabo os processos de mudança. $\mathrm{O}$ texto que ora apresentamos dedica-se à dimensão empírica deste tema, apresentando uma descrição e propondo uma análise dos desdobramentos dos processos de privatização, identificando os agentes e as condições de sua realização. As questões que buscamos responder são: Quais são os agentes que promoveram as mudanças? Como eles agiram? O que os impulsionou? O que os constrangeu? Como conseguiram impor as suas representações do processo ao restante dos funcionários? Através de quais mecanismos? Como o restante dos funcionários compôs com ou resistiu às mudanças propostas? Em suma, nosso propósito foi o de explicar como as mudanças organizacionais ocorreram, a partir da análise da dinâmica das relações sociais internas à organização.

Centramos nossa análise em uma Empresa Caso (EC), isto é, em uma variante do que ocorreu também em outras empresas. E, dentro dessa empresa, 
focamos os agentes do processo de modernização (linguagem autóctone), e as forças sociais organizadas nele envolvidas: as entidades representativas dos funcionários (sindicatos, associações profissionais, Conselho de Representante de Empregados). O fato é que uma fração dos funcionários das empresas do Setor Elétrico Paulista (SEP) interagiu e trabalhou para fazer acontecer diversas mudanças em suas respectivas empresas. Estas mudanças facilitariam a privatização das empresas, fundamentalmente as mudanças relacionadas às cisões que deram origem a novas empresas e, particularmente na EC, as mudanças relacionadas a um processo de transformação organizacional que começou por volta do segundo semestre de 1995 e teve desdobramentos até pelo menos o fim do ano de 2001.

Analiticamente, podemos dizer que, na EC, a chamada modernização ocorreu em três momentos: o primeiro pode ser identificado com a implementação do chamado de Projeto de Modernização. Esse projeto foi uma iniciativa de funcionários do alto escalão, que ocorreu entre setembro de 1995 e abril de 1996 aproximadamente. No momento em que ocorreu o segundo Projeto de Modernização, a iniciativa ganhou outra dinâmica, que envolveu direta e indiretamente um número maior de funcionários, empresas de consultoria e as diferentes forças políticas organizadas atuantes na EC. Nesse segundo momento, a iniciativa de modernização produziu uma mudança na estrutura organizacional da empresa, uma reengenharia de processos e a implantação piloto de novos processos. Por fim, o terceiro momento ocorreu após a privatização, quando os novos processos, em parte oriundos da reengenharia, foram largamente implantados. Nossa pesquisa completa abarcou os dois primeiros períodos, mas neste artigo vamos tratar somente do primeiro Projeto de Modernização, que doravante será chamado simplesmente de modernização.

Temos, portanto, que explicar como se deu a dinâmica da modernização em um contexto crítico em que os funcionários da EC sabiam que as experiências de mudanças organizacionais nas empresas, de modo geral, resultariam no desmantelamento do corpo de funcionários. Essas experiências, chamadas de downsizing (achatamento da pirâmide organizacional, especialmente com a eliminação de órgãos, postos e cargos gerenciais), tinham maior probabilidade de ocorrer se a empresa fosse estatal e se estivesse "na lista" das que seriam privatizadas, como era o caso das empresas do Setor Energético Paulista. Como foi possível constituir e dinamizar um grupo de agentes 
empenhados em realizar e promover essa modernização em um momento da história das empresas, da economia brasileira e mundial, marcado pelo predomínio de concretas e difundidas experiências de mudanças organizacionais nas empresas, as reengenharias, que, no extremo, resultavam no desmantelamento e na diminuição do corpo de funcionários das empresas em que eram implementadas? Como foi possível, dado que esses agentes sabiam que o desmantelamento do corpo de funcionários começaria prioritariamente por funcionários como eles: engenheiros, gerentes e demais funcionários que ocupavam postos conquistados em função da posse de diploma de nível de superior, que tinham uma carreira relativamente longa, premiada com aumentos salariais, benefícios e reconhecimentos correlatos à senioridade e que, por fim, gozavam de estabilidade de emprego, firmada tradicionalmente em sucessivos acordos coletivos? Neste artigo, procuraremos apresentar respostas parciais a estas questões. Fundamentalmente, vamos tratar das motivações dos agentes que empreenderam essas mudanças organizacionais.

\section{A empresa como campo: a modernização como um espaço de luta política pela imposição de sentido}

A chamada modernização é o espaço social (Bourdieu, 2001, p. 223) em que ocorreram, de forma visível e condensada, os conflitos e as alianças entre os diferentes agentes, e no qual foi produzido o impulso que mobilizou todos os envolvidos nas mudanças organizacionais e que nela trabalharam, interessados ou não.

Desta forma, podemos delimitar esse estudo a partir da estrutura deste espaço e das tomadas de posições dos agentes que nele interagiam. Os agentes da modernização definem-se a partir de um espaço de posições objetivas e de posições simbólicas possíveis. A hipótese deste trabalho é que os agentes melhor situados no espaço das posições objetivas assumem posições simbólicas homólogas, isto é, por conta das posições objetivas que ocupam, das disposições que possuem, tendem a conseguir com mais eficácia e com menos resistência a mobilização dos outros agentes, a imposição das suas representações de empresa e a canalização da energia social no sentido de sua realização.

A mudança organizacional da EC significou um processo de mobilização de seus agentes para transformá-la, no que tange aos processos de trabalho, à 
introdução de processos tecnológicos, à terceirização de atividades, à mobilização dos agentes para justificar essas mudanças frente aos seus colegas, etc. Mas, segundo a perspectiva que estamos adotando, a mudança significou fundamentalmente uma luta política pela redefinição da empresa.

Uma luta política é uma luta cognitiva (prática e teórica) pelo poder de impor a visão legítima do mundo social, ou melhor, pelo reconhecimento, acumulado sob a forma de um capital simbólico de notoriedade e respeitabilidade, que confere autoridade para impor o conhecimento legítimo do sentido do mundo social, de sua significação atual e da direção na qual ele vai e deve ir [...]. O esforço para informar e orientar a percepção, e o esforço para explicitar a experiência prática do mundo caminham juntos, uma vez que um dos móveis da luta simbólica é o poder de conhecimento, ou seja, o poder sobre os instrumentos incorporados de conhecimento, os esquemas de percepção e de apreciação do mundo social, os princípios de divisão que, num momento determinado do tempo, determinam a visão do mundo [...] e o poder de fazer ver e de fazer crer que lhe é inerente (Bourdieu, 2001, p. 226). ${ }^{1}$

Nas lutas para modificar o mundo, modificando a representação do mundo, os agentes assumem posições que dependem da sua posição objetiva no mundo social. Desta forma, o objetivo dos agentes empenhados em transformar a empresa passa, necessariamente, pela transformação das representações que eles mesmos e os outros agentes têm de si mesmos, do mundo e da empresa. A ação desses agentes depende do poder que eles têm de mudar a representação que um conjunto mais amplo de agentes tem do mundo social. $\mathrm{Na}$ perspectiva bourdieusiana, o poder dos agentes para transformar a representação do mundo social depende do capital simbólico que eles têm acumulado, quer dizer, da sua posição neste espaço social (honra, crédito, reputação, notoriedade, glória, enfim, reconhecimento). Essa posição é a condição essencial para o exercício da violência simbólica, que é o poder de impor princípios de visão e divisão do mundo, de mudar a representação do mundo (Bourdieu, 2001, p. 206).

Para dar conta das estratégias colocadas em prática pelos funcionários da EC para transformar a empresa, propomos tomar a própria "empresa como um campo", isto é, como uma unidade relativamente autônoma, determinada, também, por sua estrutura interna, produto da sua história (Bourdieu, 2000, p.

1 Grifos do autor. 
252-253). Nesta perspectiva, consideramos que as diretrizes de transformação adotadas pelos agentes da transformação dependeram das diretrizes do governo estadual, seu, então, controlador. Entretanto, consideramos que elas dependeram, também, das providências tomadas dentro da empresa, resultantes, por sua vez, da interpretação e redefinição das diretrizes do governo, feitas pelos agentes em interação e sob os constrangimentos de um campo de poder que era a própria empresa. Isso significa dizer que as transformações dependeram da estrutura das relações de força entre os diferentes agentes ou grupo de agentes constituintes da empresa, que poderiam ter perseguido estratégias diferentes, compartilhadas ou antagônicas.

Nas ocasiões em que se tomam decisões, sejam elas ordinárias ou extraordinárias, estão presentes as preocupações que os diferentes dirigentes têm (através de grupos profissionais ou de outras forças sociais) com as atividades que realizam e, assim, com suas disposições e seus interesses específicos. Neste sentido, eles procuram promover suas posições, buscando identificar seus interesses específicos com os interesses da empresa e transformar ou perpetuar o equilíbrio de forças entre as atividades e as funções que realizavam, ou com aquelas às quais seus interesses estavam ligados (Bourdieu, 2000, p. 20).

Adotando essa perspectiva, devemos buscar explicações para o engajamento dos agentes na transformação da empresa, bem como para contê-la, no conjunto das suas disposições, constituídas ao longo de suas trajetórias dentro e fora da empresa. Neste sentido, o princípio do engajamento no trabalho, a possibilidade de mudar ou não a perspectiva de carreira orienta-se no habitus historicamente constituído (Bourdieu, 2000, p. 260), um princípio de ação muito econômico que assegura uma enorme economia de cálculo (notavelmente do cálculo dos custos de pesquisa e de medida) e também de tempo, recurso particularmente raro na ação (Bourdieu, 2000, p. 262).

As estratégias dos agentes são determinadas via um inumerável conjunto de decisões que são o produto da relação entre os interesses e as disposições dos agentes situados em determinadas posições no âmbito das relações de forças existentes na empresa, e a capacidade que eles têm de fazer valer estes interesses e disposições. Isso tudo depende do peso dos diferentes agentes, ou seja, do volume e da estrutura dos seus respectivos capitais (Bourdieu, 2000, p. 94).

A modernização pode ser concebida como um locus privilegiado para a se apreender os princípios de estruturação e as forças em interação na empre- 
sa, naquele momento e naquelas circunstâncias, assim como os móveis da dinâmica dos agentes que levaram a cabo as transformações. Neste sentido, procuraremos realizar a objetivação das características pertinentes dos agentes e situá-los minimamente dentro desse espaço social estruturado. Assim, poderemos revelar os princípios de hierarquização desse espaço e relacionar as posições dos diferentes agentes com as suas práticas, realizações, resistências, justificações, condenações, etc. Poderemos, também, compreender as condições sociais que propiciaram as transformações que ocorreram, assim como conhecer e descrever os mecanismos utilizados pelos agentes para realizá-las.

\section{Recursos metodológicos}

A idéia de indivíduos eficientes (Bourdieu, 2000, p. 124) é um recurso analítico para chegarmos a essas propriedades em ação no campo (os trunfos dos agentes), via seus próprios encarnadores. Os agentes que fizeram as mudanças organizacionais na empresa são os indivíduos que influenciaram efetivamente o processo porque detinham alguma propriedade ativa no campo: controle de informação; conhecimento técnico e prático detalhado dos processos de trabalho, do pessoal, dos equipamentos, das relações entre os funcionários; relações fora da empresa: com compradores ou prestadores de serviços, com forças políticas estaduais, locais, etc. Eles foram os indivíduos eficientes, os agentes da modernização, os representantes das forças ativas presentes na empresa.

Como chegar a uma lista dos agentes da modernização? Para isso, seguimos um critério institucional, tomando os 113 indivíduos que formalmente participaram diretamente do segundo Projeto de Modernização: os representantes da Seesp, o presidente da EC e seus diretores, os funcionários de carreira, como os assessores (da presidência e das diretorias), os gerentes e chefes de departamento, de regional, de divisão, de setor, os coordenadores, os engenheiros, psicólogos, advogados, etc. Esses indivíduos foram tomados como agentes eficientes porque, além de cúpula desse projeto, eram egressos do primeiro Projeto de Modernização, isto é, eram funcionários do alto escalão da empresa que estava empenhado na modernização desde a sua gênese. Então, procuramos levantar dados sobre as propriedades pertinentes a cada um deles - idade, formação escolar, tempo de casa, cargo ou função na empresa, etc. As fontes desses dados foram: jornal da empresa (JO); documentos relativos à empresa; 
41 entrevistas e 30 questionários. Também realizamos entrevistas com agentes que não participaram da modernização e com líderes sindicais.

O presidente, os diretores e, fundamentalmente, um conjunto de funcionário do alto escalão da empresa (gerente de departamento, gerente regional, diretor, assessor de diretor, presidente e assessor da presidência) foram os primeiros a empunharem a bandeira das mudanças organizacionais internas. Vamos chamar de alto clero esse conjunto de funcionários do alto escalão da empresa que empreendeu a modernização desde o início (1995), mais o Secretário de Energia do Estado de São Paulo, e o Secretário de Energia Adjunto. Ao todo, esse grupo soma 30 indivíduos.

Os diretores, todos adventícios, tinham um montante relativamente grande de capital político. ${ }^{2} \mathrm{O}$ mesmo se aplica ao presidente, embora esse último fosse funcionário de carreira. Os outros agentes do alto clero (funcionários de carreira) vinham ascendendo aos cargos de alto escalão da empresa desde a primeira metade os anos 1980 (capital organizacional). ${ }^{3}$ Parte deles tinha relações políticas com agentes de fora da empresa, no âmbito políticopartidário, e parte deles acumulava a participação política em organizações dos funcionários desde o início dos anos 1980 (capital político). Entre esses agentes predominava a formação em engenharia, cerca de $40 \%$, havendo também uma tendência à realização de um segundo curso superior na área de economia ou de administração (cerca de 50\%), na maioria das vezes cursado após o ingresso na empresa.

Para o alto clero realizar a modernização, era preciso "enfileirar" o baixo clero, quer dizer, arregimentar os funcionários que necessariamente iriam fazer os levantamentos de dados, o detalhamento dos processos correntes e o redesenho dos novos processos, enfim, os funcionários que iriam de fato executar as mudanças. De modo geral, os agentes executores da modernização foram convocados por seus gerentes superiores, os do alto clero. Apesar do grande número de funcionários que participaram da execução, analiticamente, vamos nos centrar nos agentes que participaram direta e formalmente

2 Capital político é o conjunto das relações políticas dos agentes da EC com agentes da esfera político-partidária, de fora da empresa.

3 Por capital organizacional entendemos o tempo de casa do agente, que tem correlação com o nível do seu cargo ou da sua função. 
do segundo Projeto de Modernização: os coordenadores e os membros das iniciativas e dos grupos de apoio, que somaram, no total, 83 agentes.

Os funcionários da empresa se faziam representar coletivamente por diversas organizações que, neste artigo, chamaremos de entidades representativas dos funcionários (ERF): o Sindicato dos Eletricitários (o mais representativo), o Sindicato dos Engenheiros, a Associação dos Engenheiros da EC e o Conselho de Representantes dos Empregados (CRE). Entrevistamos membros e ex-membros da diretoria das ERF.

Em conjunto, os agentes da modernização representavam cerca de 1,6\% do total de funcionários da EC. Eles integravam os segmentos que eram conhecidos na empresa como o dos gerentes e o segmento dos universitários, assim chamados porque tinham, em sua maioria, escolaridade superior. Os dois segmentos juntos representavam cerca de $24,7 \%$ do pessoal da EC. Os agentes da modernização representavam cerca de $6,5 \%$ desses segmentos.

\section{O espaço das posições e as tomadas de posição}

O presidente da EC tomou posse no início de 1995, já falando para as autoridades estaduais e municipais, para os funcionários e jornalistas, sobre as mudanças que iriam ocorrer na empresa, embora sem tocar na palavra privatização. Ao mesmo tempo, o Secretário Estadual de Energia de São Paulo (Seesp) expunha suas prioridades para o Setor Energético Paulista (SEP): fundamentalmente, sua reorganização institucional. Em agosto de 1995, a Seesp começou a divulgar o plano de reestruturação do SEP proposto pelo governo estadual. Após essa divulgação, os presidentes das empresas do SEP se reuniram com a Seesp a fim de apresentarem seus respectivos "planos de modernização para atuar a partir da reestruturação do setor no Estado" (JO: set., 1995). ${ }^{4}$ Em setembro de 1995, o primeiro projeto de modernização foi apresentado formalmente aos funcionários da empresa, mas muitas das idéias nele contidas e das práticas a ele relacionadas já eram correntes.

4 A EC possui um jornal de circulação interna, o Jornal Organizacional. Adotamos sua sigla, JO, para identificá-lo, e , quando houver referência a alguma de suas edições, serão citados o mês e o ano da publicação, para identificar e precisar a fonte dos dados. 
Neste contexto, a Seesp visava preparar a empresa para a venda, ou modernizar a empresa para valorizá-la. Suas diretrizes básicas organizavam-se em dois eixos: primeiro, as empresas deveriam rearranjar seus ativos ("desmantelamento patrimonial”), separando as atividades de geração, transmissão e distribuição; segundo, essas atividades deveriam ser reorganizadas por unidades de negócios, caracterizadas fundamentalmente por terem a contabilidade, os centros de custos e de apuração de resultados próprios, e também por terem as atividades administrativas, financeiras, comerciais e técnicas descentralizadas, a partir da estrutura vertical inicial. Assim, após a autorização da Assembléia Legislativa do Estado de São Paulo, seriam criadas empresas subsidiárias. Com essa reestruturação, explicou a Seesp, seu objetivo era a "adaptação da empresa ao ambiente competitivo" e a sua valorização, na medida em que estava valendo " $30 \%$ do que está registrado nos livros". Enfim, naquele momento, o Estado explicitava seus objetivos, incluindo neles, de forma explicita, a privatização das empresas, através da privatização das subsidiárias que seriam criadas ou da abertura do capital dessas subsidiárias à iniciativa privada, com o Estado mantendo a posse de ações com direitos privilegiados (Golden Share) (JO, abr.-ago. 1995).

Os agentes do alto clero, por seu turno, também pretendiam preparar ou modernizar a empresa para a privatização. Sua proposta de modernização tinha cinco planos: 1) o de descentralização (o "carro-chefe"), que era destinado a ampliar a autonomia gerencial das seccionais e dos distritos da empresa, e configurá-los como unidades de negócios; 2) o de gerência por resultados ("modelo de gestão empresarial") que objetivava criar indicadores de desempenho e que projetou criar centros de resultados em cada um dos distritos; 3) o de produtividade e lucratividade, que objetivava a redução de custos, a ampliação das fontes de receitas e a priorização de investimentos; 4) o de atualização de recursos humanos, que objetivava "adequar a função recursos humanos" redimensionando, orientando e qualificando todos os níveis do quadro de pessoal, visando "obter uma melhor relação de produtividade funcional”; 5) o de atualização tecnológica, que visava a "ampliação da automação administrativa e operacional", e o aumento do "uso de recursos de informática em todas as áreas" (JO, ago.-out. 1995).

Deste modo, desde o início das atividades da nova gestão da empresa, até meados de 1996, os funcionários viram-se dispostos em um espaço social em que os pontos de vista e as ações se davam em referência à modernização, à 
privatização e à reestruturação do SEP. Neste espaço das possíveis tomadas de posição, o alto clero girava preferencialmente em torno das idéias e das ações de modernização concertadas com as diretrizes estaduais para o setor, ou seja, agia prioritariamente na arena política interna à empresa. Ao mesmo tempo, em outro pólo, os agentes lotados nas entidades representativas dos funcionários (ERF) interagiam prioritariamente na arena política externa à empresa, em oposição às mudanças institucionais em estudo e formulação pela Seesp para todo o Setor Elétrico Paulista (SEP). Temos, assim, dois núcleos de sentido principais para as ações dos funcionários da empresa, dois pólos em relação aos quais suas tomadas de posição e práticas objetivas ganhavam significado, o qual, no limite, era pró ou contra a privatização da empresa.

Em conclusão, nesse espaço social, as ERF não investiam esforços em ações contra as ações do alto clero internas à empresa. Ao contrário, atacavam apenas as ações da Seesp. Os membros do alto clero, que a partir de agora passaremos a chamar de cardeais, não investiram esforços, por sua vez, na "luta contra a privatização" nos espaços externos à empresa. Eles realizavam apenas ações que tinham um móvel interno afinado com o projeto de reestruturação do SEP. Em grande medida, eles ajudaram a Secretaria Estadual (Seesp) a estudar e propor os marcos institucionais do novo setor. Enfim, basicamente, esta foi a dinâmica dos agentes envolvidos, e este era o espaço em que interagiam até meados de 1996. Havia conflitos e ambigüidades nos posicionamentos, mas não vamos tratar deste tópico em mais detalhe nesse artigo.

\section{Os móveis da ação e o projeto salva-vidas}

O processo de modernização da Empresa Caso (EC), antes de sua privatização, foi bastante singular. Essa singularidade pode ser explicada por uma combinação de fatores que vão, desde a tomada de posição das ERF pela ação externa, por suas fraquezas e ambigüidades, até os fatores que davam sustentação social às ações do alto clero, tais como a posição da EC em relação às outras empresas do SEP, as relações sociais privilegiadas e o conseqüente acesso a informações privilegiadas por parte do alto clero, os estigmas correntes, relativos aos funcionários das empresas estatais, as mudanças morfológicas em curso no setor; as expectativas de carreira do alto clero e, por fim, a forma particular de reação do alto clero a todos esses fatores, a partir das suas disposições socialmente constituídas. Nosso objetivo neste texto é, a 
partir da análise dessas disposições, apresentar os móveis das ações dos cardeais da modernização.

Os cardeais da modernização ocupavam uma posição que lhes dava acesso preferencial e antecipado às informações sobre a empresa e sobre as diretrizes para o seu futuro, basicamente às informações provenientes das decisões e dos propósitos do governo estadual, da presidência e das diretorias da empresa. Tinham acesso a essas informações privilegiadas porque tinham relações sociais privilegiadas, pertenciam a grupos de poder na esfera estadual e na empresa. Em maior ou menor grau, eles deviam suas posições no alto escalão da empresa a um arranjo de determinantes que iam desde "puro" capital político, ao "puro" capital organizacional e escolar.

Devido a essas relações sociais privilegiadas, antes que os demais funcionários da empresa, os cardeais da modernização tinham a percepção de que a política governamental de privatização seria levada a cabo. E ainda, devido a essas relações, eles tinham melhor percepção sobre a posição da empresa, sobre a posição deles próprios no campo das empresas e sobre a posição dos agentes das empresas do SEP. Assim, já em 1995, eles tinham a crença arraigada de que a EC seria uma das primeiras a ser privatizada no SEP.

A visão que realmente nós íamos ser privatizados era uma consciência. Veja, a [outra empresa do SEP] era nossa controladora e nós sabíamos que eles não iam dar os ossos deles primeiro, então nós tínhamos certeza que nós iríamos ser privatizado (Engenheiro, alto clero e ex-funcionário).

Em conseqüência dessa crença, começaram a interagir em torno da questão de qual seria o futuro da empresa e o futuro deles próprios como gerentes, executivos e dirigentes. No espaço das possíveis tomadas de posição, os cardeais da modernização, em alguma proporção, eram constrangidos pelos seus atrelamentos políticos na esfera estadual e, assim, tinham que seguir algumas diretrizes relativas às obrigações recíprocas inerentes às indicações que os fizeram chegar às posições que ocupavam na empresa no momento, e em outros espaços em momentos anteriores. Alguns deles já tinham ocupado cargos homólogos ou superiores em autarquias ou empresas públicas municipais, estaduais e federais, além de muitos serem integrantes de partidos políticos. Outros eram funcionários autóctones que atuavam como assessores e gerentes de diretores adventícios, que, ao serem incorporados mostravam-se 
pouco socializados com as rotinas e os processos de trabalho da empresa e com o seu corpo de funcionários.

Em grande medida, outros móveis importantes das ações dos cardeais da modernização foram os estigmas relativos ao seu conhecimento técnico, ao seu desempenho profissional e aos seus rendimentos na forma de salários e benefícios. Os cardeais reconheciam que eles e seus congêneres em empresas estatais e, principalmente, os funcionários do baixo clero da EC, de modo geral, eram estigmatizados no "mercado", ou seja, fora da empresa, no espaço profissional e no espaço empresarial. Em suas representações, o espaço profissional era visto de modo bipartido: de um lado estavam os profissionais de dentro da EC, ou das empresas estatais de modo geral, e, do outro, estavam os profissionais de fora da empresa, os que atuavam no "mercado". Neste esquema de representação é que dá sentido ao estigma da "acomodação". No que tange aos conhecimentos de cada área de atuação, e aos conhecimentos das tecnologias de informática, de gestão e de finanças de modo geral (custos e rentabilidade), reconhecidos como típicos das empresas privadas, os cardeais do alto clero, em maior ou menor medida, viam-se como desatualizados, menos qualificados, menos informados, etc., em decorrência da acomodação que o "modelo estatal" possibilitava.

$\mathrm{Na}$ verdade todo mundo que era do setor elétrico estava há 20 ou 30 anos dentro do modelo estatal [...]. Todos os dirigentes da empresa foram criados nessa mentalidade monopolista. Quando você passa para a iniciativa privada, em que você tem que dar valor ao cliente, em que o modelo previa uma concorrência entre todas as empresas [...], previa competição [...]. Para isso você precisa ter pessoas preparadas dentro da empresa [...]. Então, veio muita gente trabalhar na empresa: do mercado financeiro que era um mercado agressivo, do comercial, [...] que eram pessoas que, pelo menos na teoria, sabiam lidar com esse mercado livre [...]. Eles aprenderiam coisas com essas pessoas competentes [da EC] e ensinariam coisas a essas pessoas, e aí a empresa poderia se adequar ao modelo que se pretendia (Advogado, alto clero, ex-funcionário).

Estes cardeais não tinham como escapar de uma outra dimensão do estigma: a "pecha" que desqualificava seu desempenho profissional, ao classificá-los como ineficientes, incompetentes e improdutivos. Em alguma medida, essa representação também era internalizada pelos funcionários das empresas estatais, atribuindo o estigma a si próprios, e, principalmente, aos outros membros de sua categoria profissional. 
Quem é do dono antigo sempre parece que tem um carimbo na testa assim: "pô esse cara é incompetente, não trabalha direito'. Quem é bom é só quem chega. Tudo isso existe infelizmente porque é típico da mediocridade do ser humano [...]; taxar as pessoas e colocar alguns estigmas nas pessoas. Então quem vem de uma... quem é de uma empresa privada falava: "pô todo mundo que tava, quem é de uma empresa estatal é incompetente, é isso, é aquilo, é corrupto e coisa que o valha'. Tem essa pecha (Engenheiro, alto clero, ex-funcionário).

Por fim, eles se percebiam e eram classificados, pela sociedade de modo geral e pelo empresariado de modo particular, como pertencentes ao segmento dos funcionários que recebia altos salários (chefes, ex-chefes, gerentes, exgerentes, assessores, ex-assessores, diretores, ex-diretores, etc.), sendo que esse segmento teria uma dimensão maior do que a necessária.

Então, houve um movimento que era até previsível. Ela [EC] cortou, e cortou bastante, esse pessoal que era o pessoal mais caro, tanto esse pessoal que era o plano 3 [pessoal que tinha nível superior], como níveis de chefia, inclusive, [plano 4: gerentes e chefes]. O pessoal do nível de chefia se cortou drasticamente porque era um pessoal caro. E havia uma distorção também que explica em parte o inchaço, digamos, do plano 3. Em geral, o pessoal com nível de chefia na empresa era o pessoal que tinha nível superior. E além de ter formação superior ele exercia um cargo de chefia. Aí, quando mudava governo, o sujeito perdia o cargo, às vezes de gerente [...], mas ele continuava trabalhando como plano 3 [...]. Então, você acabava criando um conjunto de ex-chefes e ex-gerentes que continuava trabalhando como profissional. [...] Não mudava o salário, o salário incorporava o salário de gerente, mesmo que ele saísse do cargo (alto clero, ex-funcionário). ${ }^{5}$

Os cardeais reconheciam os problemas e o estigma, mas, ainda que procurassem se colocar individualmente como distintos ("nem todos"), não tinham como escapar da desclassificação generalizante. Tratava-se de representações difusas na sociedade, absolutamente fora de controle, nas quais eles se viam envolvidos, sendo a elas vinculados de forma indiscriminada. Tratava-se de uma desclassificação relacionada ao fato de terem trilhado sua carreira exclusivamente em uma empresa estatal e monopolista. Da mesma forma que o baixo clero, em grande medida, eles eram considerados velhos, antigos, de uma era que acabou ("fim de uma era”): “- Vocês aí de estatal!

5 Não apresentamos dados sobre a escolaridade desse e de outros entrevistados para evitar sua identificação. 
No fundo, era isso que se dizia: - Vocês são todos um bando de eletrossauros" (alto clero, ex-funcionário).

Os cardeais da modernização estavam expostos, também, aos constrangimentos devidos às mudanças morfológicas em curso no setor elétrico de modo geral, especialmente no que tange à contração do quadro de funcionário desde o início dos anos 1990. Um dos corolários dessas mudanças foi o acirramento da disputa pelos postos do alto escalão nas empresas. Um caso exemplifica esse processo: no caso específico da EC, os cardeais formavam um segmento no plano de cargos e salários - Plano 4, "Chefes e Gerentes" que constava como acessível aos funcionários que pertenciam ao segmento imediatamente inferior - Plano 3, "Universitários". Em dezembro de 1995, esse primeiro segmento representava $7,5 \%$ do pessoal da empresa, enquanto segmento imediatamente inferior representava $18,5 \%$. Em poucas palavras, os cardeais estavam diante da pressão dos colegas que esperavam uma vaga, assim como da pressão dos que estavam querendo retomar uma vaga perdida em função da chamada "gangorra estatal". Em acréscimo, e certamente o mais importante, com a confirmação de sua crença de que a EC seria privatizada, dado que ainda faltavam muitos anos para a sua aposentadoria, estariam vulneráveis por ocuparem posições que seriam disputadas por novos colegas que viriam de fora da empresa.

Além do tempo de carreira que tinham pela frente, outro fato impulsionava os cardeais a se engajarem na modernização. Eles estavam no último degrau possível da carreira dentro da empresa, tinham de 8 a 15 anos de trabalho pela frente até a aposentadoria, e já tinham atingido o teto de vidro, seja em status, seja em remuneração. Podemos considerar que, em alguma proporção, a privatização da empresa representava uma possibilidade de romper esse teto. Por exemplo, os engenheiros que estavam entre os cardeais do alto clero (40\%) tinham um montante de capital escolar ${ }^{6}$ e organizacional que lhes permitia disputar as posições dos diretores indicados politicamente. Dessa forma, afora o capital político, os engenheiros da casa ombreavam-se confortavelmente com os engenheiros diretores adventícios. Este é o caso de um dos principais cardeais da modernização. Em meados de 1990, ele já era gerente de departamento, assistente de diretoria, e as expectativas eram de

6 Consideramos capital escolar o conjunto dos cursos escolares que os agentes possuíam a partir do nível superior. 
que ele seria o próximo diretor. Mas o novo diretor não saiu dos quadros da empresa, foi indicado por um partido político.

Ele era um cara muito capaz e encarreiramento. Já na época quando o [nome de pessoa] era diretor, o [nome do cardeal da modernização] já era gerente de departamento, uma posição abaixo do diretor. Quer dizer, já estava no meio. Inclusive quando houve a mudança de governo, muita gente achou que ele seria o diretor, já na época. Então, ele tinha toda a postura para ser o diretor. Não foi o diretor e acabou sendo o coordenador desse processo de modernização (administrador, baixo clero, ex-gerente de setor).

Em resumo, os cardeais da modernização estavam constrangidos por seus atrelamentos políticos na esfera estadual, mas também estavam diante da possibilidade de uma participação antecipada em projetos de mudança, o que, em alguma medida, poderia significar uma salvaguarda em relação às pressões colocadas pela morfologia do presente e em relação às incertezas da morfologia do futuro. Desta forma, com a modernização, eles poderiam se livrar dos estigmas que seriam suas marcas de saída nas disputas internas futuras, ou seja, eles estavam tomando posições claras através das quais esperavam distinguirem-se como "capazes de gerir, de modernizar" (alto clero, ex-funcionário) e que, conseqüentemente, poderiam abrir-lhes as portas para os cargos superiores que, após a privatização, não estariam mais ao sabor das indicações políticas.

Enfim, o impulso externo para mudar a empresa e privatizá-la encontrou reciprocidade dentro da empresa, num conjunto de agentes que, embora pequeno, era dotado de poder institucional e simbólico para agir sobre a representação dos outros agentes e, assim, transformar a empresa transformando a representação que os agentes dela tinham.

Outra parte de nossa argumentação é que a iniciativa da modernização empreendida pelo alto clero foi fruto da aplicação de seus sistemas de percepção ao espaço em questão. Essa iniciativa era a forma particular possível que encontraram de se adiantar ao futuro, tal como ele era percebido e definido por um habitus resultante de um processo de socialização que se deu na esfera do alto escalão da empresa, desde os anos 1980.

Os agentes do alto clero, como a maioria dos funcionários da empresa, eram portadores desse habitus, formado em um mundo organizacional fundamentado em uma lógica industrial: modelo de empresa clássico dos enge- 
nheiros, que a EC instituiu nos anos $1970 .^{7}$ No entanto, desde o início dos anos 1980 até meados dos anos 1990, além de terem ascendido a cargos gerenciais via concursos internos, eles vinham ascendendo na hierarquia organizacional da empresa e alcançando posições a partir das quais capitanearam programas e práticas de mudanças organizacionais, tais como: o Movimento de Participação dos Funcionários; a instituição do Conselho de Representantes dos Funcionários; o programa de Gestão Participativa por Objetivo; organização e difusão do programa de Qualidade Total.

Esses programas, em alguma medida, produziam e reforçavam habitus distintos em relação ao que predominou na sua socialização. Todos esses programas e práticas podem ser enquadrados, com algum nível de equivalência, como contestadores de fundamentos do modelo de empresa dos anos 1970. De modo considerável, conceitos, metodologias e práticas organizacionais estranhas ao modelo clássico de empresa foram introduzidos no repertório cognitivo dos funcionários da EC. Por um lado, formas predominantes até então, que enquadravam a hierarquia na divisão entre concepção e execução do trabalho e as divisões internas da empresa à formação especializada; por outro, enquadramento da empresa em um modelo baseado em processos, que desconsidera, em grande medida, as divisões funcionais da estrutura organizacional, que considera as partes da empresa como unidades que podem ser operadas independentemente, administradas autonomamente em várias dimensões que prestam serviços umas às outras. E, por fim, enquadramento da empresa num modelo que considera viável o rearranjo dos processos como meio de diminuir custos, que considera que a organização do trabalho e a organização dos processos de trabalho podem ser pensadas fora dos quadros da estrutura organizacional funcional, que as atividades podem ser terceirizadas para diminuir custos, que os insumos e os processos podem ser recombinados e rearranjados para diminuir custos.

7 Teoricamente, há um modelo de empresa típico dos engenheiros e um habitus de engenheiro que se constituiu desde o início do século XX. A partir desse modelo, tanto os engenheiros quanto os gerentes industriais enquadram a empresa como um todo expansivo e inclusivo. Esta é a fórmula de fundo que orienta a sobrevivência das organizações, através do controle contínuo das incertezas, via a endogenização de atividades para serem coordenadas e controladas por uma estrutura organizacional verticalizada (estrutura divisional, com diretorias, departamentos, divisões, setores, seções, subseções, etc.). Essa estrutura é perpassada por uma divisão estanque entre concepção e execução do trabalho (Zilbovicius, 1999; Fligstein, 1993; Veblen, 2001). 
Essas formas diferentes de enquadramento cognitivo da empresa estavam presentes no contexto da EC. Em alguma medida, elas já se inscreviam nas disposições dos seus funcionários, flexionando o habitus clássico dos engenheiros e gerentes industriais. Certamente isso ocorreu de modo menos intenso com aqueles que estavam à margem dos programas, e de modo mais intenso com os que estavam no núcleo dos programas: os organizadores, os monitores e os multiplicadores. Em grande proporção, os que estavam no núcleo dos programas constituíram o conjunto de agentes da modernização, o chamado alto clero. Dessa forma, as disposições relacionadas a esses programas, já presentes no espaço social dos executivos e gerentes brasileiros, estavam presentes no espaço homólogo da EC e constituíam o substrato cognitivo e as disposições mais próprias, mais locais dessa região do espaço, ou seja, mais características do habitus dos cardeais da modernização.

A partir de 1995, essas disposições orientaram a forma particular de reação do alto clero às iniciativas da Seesp em relação ao SEP e às suas empresas. A fórmula básica que orientava suas preferências nos momentos de decisão pela modernização, e durante a implementação do projeto de modernização, era a rejeição ao modelo de empresa vigente - modelo clássico de empresa dos anos 1970 -, algo que, de certa forma, eles vinham fazendo desde os anos 1980. Eles rejeitavam um "modelo" chamado de "estatal e monopolista" e buscavam conduzir a empresa a um "novo modelo" que, embora ainda não estivesse definido, estava sendo desenhado através da exclusão e da oposição aos elementos que pudessem lembrar o "modelo estatal", e também pela inclusão do que pudesse ser associado à noção de "iniciativa privada".

Pessoalmente, eu posso dizer uma coisa: eu li muitas coisas. Fui ler o livro de reengenharia do Michael Hammer, o de qualidade do Deming, peguei um monte de coisas. Até em inglês às vezes eu comprava e tal. O que está acontecendo? O que é essa revolução? Para tentar entender pelo menos... De repente nós tivemos um choque do futuro, vamos dizer assim. Aí falou: - Pô o que aconteceu aqui? Vai mudar. O que está acontecendo aí fora? [...]. Enfim, eu diria também que as pessoas que estavam ali tinham, digamos, uma capacidade profissional e tal diferenciada. Eram pessoas que já exerciam cargos gerenciais, que tinham uma formação superior e que aí saíram correndo atrás das coisas, lendo artigos, lendo revistas de negócios (alto clero, ex-funcionário).

A posição dos cardeais no espaço social do processo de privatização e reestruturação da EC e sua sintonia com seu habitus específico orientavam as 
percepções dos integrantes desse grupo acerca das diretrizes impostas pelo presente, bem como as suas reações a essas diretrizes, na medida em eles levavam em conta um futuro possível, que também era uma percepção resultante do habitus e da posição desses mesmos agentes no espaço social. São essas percepções e antecipações, dentre as possíveis, que explicam, em parte, a posição por eles tomada e as práticas por eles adotadas para conservar ou subverter o presente.

A idéia era fazer o projeto de modernização e vender para os novos controladores a idéia de que a empresa já tinha um projeto de modernização [...]. Façamos a revolução antes que o povo a faça, porque foi um pouco isso. Falou: - Oh! Vai ser vendida! Foi uma surpresa tremenda. [...] Eu diria, aspas, que a resistência que aconteceu foi uma tentativa do corpo gerencial e dos dirigentes de falarem:Oh! Vamos fazer uma coisa, vamos preparar, vamos fazer uma modernização da empresa com a expectativa de que, quando isso aqui for privatizado, esse plano de modernização será encampado, será aceito pelo novo controlador. E aí, a empresa já perdeu funcionários, seria menos dramático o reajuste[...]. Enfim, havia essa idéia do plano de modernização de falar: - Nós vamos pegar a empresa e transformá-la em mais eficiente, mais moderna para quando o novo dono chegar falar: - Bom eu vou ficar com estas pessoas, estas são as pessoas que já demonstraram que têm uma certa capacidade de gerir, de modernizar, então, não vou ficar procurando gente fora, não vou fazer um corte brutal de pessoal, vou manter (alto clero, ex-funcionário).

A idéia de se antecipar aos novos controladores como meio de demonstrar que a empresa e determinados agentes tinham a capacidade de se modernizar e, assim, serem considerados distintos internamente e estarem "à altura" dos pares de fora, era corrente entre os cardeais da modernização. Certamente suas iniciativas tinham que atender aos propósitos do governo de preparar a empresa para vender, ou modernizar a empresa para valorizá-la. Mas as diretrizes do governo encontraram eco em propósitos do alto clero que, a partir de sua posição no espaço social da empresa, também pretendiam prepará-la ou modernizá-la, para que o novo dono reconhecesse que alguns dirigentes tinham capacidade de gerir, de modernizar, e que não era preciso procurar ou trazer gente de fora. Isto significa que dentro da empresa havia agentes que, em função das suas posições e das suas disposições, decidiram se alinhar, por antecipação, aos novos acionistas que viriam, vendo nisso um meio de salvaguardar ou alavancar suas posições. Os empreendimentos da modernização produziram uma dinâmica específica no interior da empresa, 
na medida em que a abertura semântica dos termos preparar a empresa, ou modernizar a empresa permitiu que o alto clero acrescentasse-lhes significados que englobavam possibilidades mais convenientes para a sua posição presente.

Eles decidiram pela realização de um downsizing que fosse conduzido por eles próprios, ao invés de ficarem expostos a um possível takeover (tomada da direção da empresa pelos novos acionistas, muitas vezes de modo hostil) em um futuro próximo, a partir da privatização. Eles decidiram deflagrar antecipadamente o processo de inovação tecnológica e de reconfiguração da empresa e de seus cargos, antecipando-se, assim, às disputas que ocorreriam no futuro, em um momento em que seus rivais mais próximos já estariam dentro da empresa.

Os cardeais da modernização não foram simplesmente constrangidos ou, mesmo, determinados por uma dinâmica exterior que levaria à privatização da empresa, à sua reestruturação organizacional, a inovações tecnológicas, etc. Eles contribuíram para prescrever e fazer com que esses processos acontecessem. Em grande medida, a decisão política interna à empresa precedeu os constrangimentos de cunho econômico, tecnológico, político, etc. Nossa interpretação é a de que a iniciativa da Seesp de preparar a empresa para a privatização ganhou várias dimensões concretas, criativas e instigantes porque recrutou agentes que fizeram mais do que seguir ou cumprir as diretrizes governamentais. Eles criaram um projeto de mudanças na empresa, a partir de uma lógica interna, mais afinada com as diretrizes e os objetivos latentes do Estado do que poderia ser esperado pela Seesp: "inclusive, nos últimos dois anos, eu ficava fazendo palestra de como nós estávamos preparando. Ninguém acreditava, e nós fomos pioneiros" (Engenheiro, alto clero, ex-funcionário).

A chamada modernização foi uma invenção que permitiu, por um lado, que seus inventores transcendessem seus limites, perseguindo objetivos específicos, relacionados à sua posição e às suas representações das transformações do espaço social interno e externo à empresa. Por outro lado, a forma assumida por esse processo permitiu dissimular e legitimar a subversão dos contratos que historicamente eram mantidos implícita e explicitamente com o corpo de funcionários - prioridade no mercado de trabalho interno, carreira segura, benefícios previdenciários, etc. -, por meio de um pretenso universalismo que se legitimou através de prescrições que possuem um caráter polissêmico, como a de preparação ou modernização para a privatização, assim 
como a idéia de participação - conceito historicamente arraigado na representação dos funcionários.

Gostaríamos de ressaltar que essas ações não se deram de forma voluntariosa. Elas resultaram de um conjunto de micro-constrangimentos e microexpectativas que se fortaleciam umas às outras.

\section{Alguns desdobramentos}

Podemos apresentar alguns dos desdobramentos das ações dos agentes no espaço social do qual estamos tratando. Um deles é o de que, com um mínimo de legitimidade e de realizações em seu ponto de partida, as ações do alto clero tiveram o efeito de abrir algumas alternativas para a empresa, para os funcionários e para alguns de seus segmentos. Não dizemos, com isso, que desde o seu início a modernização teve grandes efeitos sobre a empresa ou seus funcionários. Os cardeais da modernização reconhecem que tiveram dificuldades para levar o processo adiante. De qualquer forma, vários de seus projetos e planos foram realizados. Em conseqüência, os projetos de modernização subseqüentes puderam funcionar em sua plenitude, sendo capazes de atingir um dos seus objetivos principais, que era o corte de cerca de $45,5 \%$ do pessoal empregado, que ocorreu entre 1996 e 2001. Ironicamente, em termos proporcionais, os agentes da modernização formam os mais atingidos por esse corte.

As realizações objetivas tiveram o efeito de reforçar o sentido das ações propostas. Deve-se somar a isso o fato de que pelo menos alguns desses sentidos eram compartilhados por outros segmentos de funcionários e, desta forma, minimamente legítimos no âmbito da empresa. Isso incluiu na trama diversos segmentos dos funcionários, e teve como desdobramento o enfraquecimento de suas entidades representativas (ERF), mesmo das mais combativas.

O que se pode perceber é que o alto clero conseguiu, em grande medida, impor a sua representação de empresa e canalizar a energia social no sentido de torná-la real. As explanações dos cardeais compõem um quadro de violência simbólica que induziu à desvalorização dos saberes técnicos especializados por áreas, típicos do modelo de empresa de engenheiros e gerentes industriais. Essas explanações demonstram que os conflitos latentes foram se tornando progressivamente avivados, sendo essa uma das causas do enfraquecimento da combatividade sindical e dos outros segmentos dos funcionários. 
Em meados de 1996 foi anunciado que a modernização entraria em uma nova fase. Desde então, o pânico tomou conta dos funcionários. É neste contexto que o segundo projeto de modernização teve início. Mas esse será o tema de um outro artigo.

\section{Referências}

BANCO NACIONAL DE DESENVOLVIMENTO ECONÔMICO E SOCIAL BNDES. Privatização no Brasil: 1990-1994; 1994-2002, 2002 (publicação preparada pela área de desestatização e reestruturação. Disponível em $<$ http://www.bndes.gov.br $>$ ).

BAUDELOT, C.; GOLLAC, M. L'informatique au travail. Actes de la recherche en sciences sociales, Paris, n. 134, p. 03-21, 2000.

BIAZZI, L. A. et al. Descentralização e privatização nos setores de infra-estrutura no Estado de São Paulo. São Paulo: Fapesp/Edições Fundap. 1999.

BOLTANSKI, L.; CHIAPELLO, E. Le nouvel esprit du capitalism. Paris: Gallimard, 1999.

BOURDIEU, P. La noblesse d'état: grandes écoles et espirit de corps. Paris: Les Editions de Minuit, 1989.

—. Les structures sociales de l'économie. Paris: Seul, 2000.

- Meditações pascalianas. Tradução Sergio Miceli. Rio de Janeiro: Bertrand Brasil, 2001.

COLE, R. Strategies for learning: small-group activities in american, japanese, and swedish industry. Berkeley: University of Califórnia Press, 1990.

FLIGSTEIN, N. The Transformation of corporate control. Cambridge: Harvard University Press, 1993.

GOLLAC, M. et al. Informatisation: l'entrée du marché dans l'organisation. Revue française de gestion, Paris, n. 118, p. 102-114, 1998.

GRÜN, R. Modelos de empresa, modelos de mundo: sobre algumas características culturais da nova ordem econômica e da resistência a ela. Revista brasileira de ciências sociais, v. 14, n. 41, p. 121-140, 1999.

HENRY, O. Entre savoir et pouvoir. Actes de la recherche en sciencies sociales, Paris, n. 95, p. 37-54, 1992.

LEAL FERREIRA, C. K. Privatização do setor elétrico no Brasil. In: PINHEIRO, A. C.; FUKASAKU, K. (Eds.). A privatização no Brasil: o caso dos serviços de utilidade pública. Rio de Janeiro: BNDES, 2000. p. 179-220.

LOUREIRO, M. R. L'internationalisation des milieux dirigeants au Brésil. Actes de la Recherche en sciences sociales. Paris, n. 121/122, p. 42-51, 1998. 
PEDROSO NETO, A. J. A privatização do setor elétrico paulista: suicídio de um grupo. Tese (Doutorado em Ciências Sociais) - Programa de Pós-Graduação em Ciências Sociais, Universidade Federal de São Carlos, 2005.

PIALOUX, M. Stratégies patronales et résistences ouvrières. Actes de la recherche en sciences sociales. Paris, n. 114, p. 5-20, 1996.

PINGELLI, R. L.; TOLMASQUIM M. T.; LINHARES, J. C. A reforma do setor elétrico no Brasil e no mundo: uma visão crítica. Rio de Janeiro: Relume Dumará, 1998.

TAVARES DE ALMEIDA, M. H. Negociando a reforma: a privatização de empresas públicas no Brasil. Dados, Rio de Janeiro, v. 42, n. 3, 1999.

TOLMASQUIM, M. T.; OLIVEIRA, R. G.; CAMPOS, A. F. As empresas do setor elétrico brasileiro: estratégias e performance. Rio de Janeiro: Edições Cenergia, 2002.

VEBLEN, Thorstein. The engineers and the price system. Kitchener: Batoche Books, 2001.

VILLETTE, M. Sociologie du conseil en management. Paris: Éditions La Découverte, 2003.

ZILBOVICIUS, M. Modelos para a produção, produção de modelos: gêneses, lógica e difusão do modelo japonês da produção. São Paulo: Fapesp/Anablume. 1999. 